\title{
The Relationship between Oil Prices and Exchange Rate: The Case of Romania
}

\author{
Asst. Prof. Dr. Ahmet Şahbaz (Gaziantep University, Turkey) \\ Asst. Prof. Dr. Uğur Adıgüzel (Cumhuriyet University, Turkey) \\ Asst. Prof. Dr. Tayfur Bayat (İnönü University, Turkey) \\ Asst. Prof. Dr. Selim Kayhan (Bozok University, Turkey)
}

\begin{abstract}
This study investigates to causality between crude oil prices and exchange rates in Romania employing monthly data from the beginning of floating exchange regime for November 2004 to December 2011. The study benefits from the recent advance in the time series econometric analysis and carries out non-linear causality and frequency domain causality tests. According to nonlinear causality test results there is no causality between the variables. Results show that frequency domain causality results slightly differentiate from the nonlinear causality analysis and imply that there is a causality running from real exchange rate to real oil price on the mediun and long run.
\end{abstract}

\section{Introduction}

The term of transition economy includes the countries located in Central and Eastern Europe. The common point of these countries is strong change in their economic structure. The defining characteristic of the transition countries is their decision to abandon central planning as the principal mode of organizing their economies and to move to market-oriented economies with significant private ownership of the means of production (IMF, 2000). Romania was included in the list of transition countries in 1989.

The country experienced different stages of development in the period including years between years 1989 and 2011. After the economic decline and recovery periods, Romania participated to European Union in 2007. International Money Fund, World Trade Organization and European Bank for Reconstruction and Development are the other institutions which Romania joined in the last sub-period of the transition process.

By the beginning of transition period in Romania, a number of major reforms were made in the fields of privatization, price liberalization, banking and commercial law and regulations in financial system and financial institutions in order to participate global economic system. Another important reform was made in trade and foreign exchange rate system of Romania. Similar to other transition countries, Romania has started with a fixed exchange rate regime and moved gradually from an intermediate (soft peg) regime to a managed floating regime (Marcu, 2008). The National Bank of Romania started to apply controlled (managed) floating regime in 1999 (Dobrota, 2007). Finally the Bank has started to implement floating regime by the beginning of inflation targeting regime in November 2004. Transition to floating exchange rate regime allows to external factors to induce exchange rate fluctuations.

By the beginning of transition period, the Romanian economy has grown remarkably. The growing economy has induced to increase energy demand. According to Eurostat database, the primary energy demand was 34 million tonnes of oil equivalent (MTOE) in 1999, it was more than 38 MTOE in 2008. Although a contraction occured in energy consumption because of global crisis in 2008, it has increased again by the end of crisis.

Romania meets its energy demand mainly from its own sources. In this regard, its energy import dependency is lower than European Union avarage. On the other hand, a quarter of total primary energy supply is met by oil. Romania is a significant producer of oil. Domestic oil production covers a large percentage of oil needs. Oil dominates the primary energy supply of Romania with gas and solid fuels. Romania imported oil more than 4.8 MTOE, while it produced 6 MTOE in 2004 (EC, 2007). $40 \%$ of imported energy is in the form of crude oil imported mainly from the Russian Federation and Kazakhstan.

In addition to transition to floating exchange rate regime in November 2004, increasing energy demand parallel to economic growth brings to question that "Do oil price fluctuations induce exchange rate fluctuations in Romania?". In the light of these explanations, we examine the causation linkage between real exchange rate and oil price in Romania. We employ monthly data from the beginning of floating exchange rate regime in November 2004 to December 2011. The causal relationship is identified by employing multiple testing approaches. In that respect we employ linear causality test developed by Hatemi-J (2006) and frequency domain causality test developed by Breitung and Candelon (2006).

The contribution of this study is two fold. First, the determination of causation linkage has important policy implications. The fluctuations in exchange rate impairs on economic growth (Rickne, 2009). In this regard, reducing price volatility of oil also proves exchange rate stability and hence economic growth. On the other hand, the information about possible interaction between oil prices and exchange rate plays crucial role in 
making long term energy policies. By determining the causation linkage, policymakers might tend to alternative energy sources in order to reduce oil dependency and oil demand. In the light of results, we also provide information for global investors in investment decisions. By monitoring oil prices, investors may forecast exchange rate movements. Besides, financial market actors and speculators could be able to identify portfolio diversification options in exchange rate markets. Secondly, this study also attempts to compare time domain and frequency domain causality analyses approach which generates test statistics at different frequencies across spectra. By doing so, we examine the existence of causality between variables in different time frequencies. This would give opportunity to test Coudert et al.'s (2008) findings about the differences in price elasticity of oil demand and supply in different time periods.

The rest of paper is organized as follows. The next section devoted to summarize theoretical interpretations about the linkages between variables. The third section summarizes the existing literature investigating the relationship between variables. In the fourth and fifth sections, econometric methodology and the data are described. In the section six, empirical results are presented. We summarize and conclude empirical findings in the last section.

\section{Theoretical Background}

Theoretically there is a number of variables affect exchange rates in floating exchange rate regime. The economists have investigated the effects of possible variables on exchange rates. In this regard, real factors as well as nominal factors are examined. While Branson (1981) attributes an important role to monetarial factors, Dornbusch (1980), Bergstrand (1991), Faruquee (1995), Clarida and Gali (1994), Mark and Choi (1997) find the significant effects of real variables.

On the other hand, Golub (1983) and Krugman (1983a and 1983b) attributes an important role to oil price shocks in definition of exchange rate fluctuations. While Golub (1983) explains the relationship via wealth transfer channels, Krugman (1983a and 1983b) argues that exchange rates differentiate due to import preferences and investment decisions of oil exporting countries in the case of oil price increases.

On the other hand, Coudert et al. (2008) suggest that a shock in U.S. dollar exchange rate also affects oil prices. They explain the relationship as follows: oil pruchases are paid in dollars. Demand depends on the domestic price for consumer countries which changes with the dollar fluctuations. Depreciation in dollar reduces the oil price in domestic currencies for countries with a floating currency (Coudert et al., 2008). This leads to an increase in real income of consumer countries and increases oil demand. So, dollar depreciation increases oil demand and this would increase oil price. Similarly, a U.S. dollar depreciation has effects on oil supply. The depreciation in U.S. dollar can also trigger inflation and reduce the income in oil producer countries, the currencies of which are linked to the dollar. The increase in inflation and the decrease in purchasing power reduce the real disposable income and therefore the income available for drilling, everything else equals (Coudert et al., 2008). As a result, dollar depreciation may result in a reduction in oil supply, henceforth oil price. But the effects of exchange rate shocks on oil demand and supply can be observable on the long run. Because the price elasticity of both demand and supply are inelastic on the short run. So the effect of exchange rate on oil price occurs on the long run.

\section{Literature Review}

In this section we focus on the literature analyzing exchange rate and oil price relation. We classify the literature into four groups. The first group of studies supports evidence of causality running from oil price to exchange rate. Amano and van Norden (1998) for the U.S.A. and Chaudhuri and Daniel (1998) for sixteen OECD countries support evidence for this argument. In latter studies, Aleisa and Dibooglu (2002) for Saudi Arabia, Akram (2004) for Norway, Kutan and Wyzan (2005) for Kazakhstan, Zalduendo (2006) for Venezuela, Issa et al. (2006) for Canada, Olomo and Adejumo (2006) for Nigeria, Chen and Chen (2007) for G7 countries, Coudert et al. (2008) for U.S.A., Narayan et al. (2008) for Fiji Islands, Korhonen and Juurikkala (2009) for nine OPEC countries, Nikbakht (2010) for seven OPEC countries, Hasanov (2010) for Azerbaijan, Dawson (2003) and Mendez-Carbajo (2011) for Dominic Republic and Lizardo and Mollick (2010) for Canada, Mexico, Norway and Russia as oil exporting countries and for Denmark, Japan, Sweden, the United Kingdom and the Euro area countries as exporting countries reach similar results with Amano and van Norden (1998).

Second group of studies implies that real exchange rate shocks induce oil price fluctuations and indicates a causality runing from real exchange rates to oil prices. Indjehagopian et al. (2000) find that variation in exchange rates has an instantaneous impact on the variations in oil prices for Holland, Germany and France. In another study for developed country context, Sadorsky (2000) analyzes U.S.A. and obtains that exchange rate induces crude oil future prices. This view is supported by Schmidbauer and Rösch (2008) and Zhang et al. (2008), Yousefi and Wirjanto (2004) for Indonesia, Iran, Nigeria and Saudi Arabia; Yousefi and Wirjanto (2005) for Iraq, Kuwait and Venezuela. 
The third group of studies finds evidence of two way causality (the feedback relation) between oil price and real exchange rates. In their initial studies Usama and Normee (2009) imply that there is a bi-directional causality between variables in the short run in United Arabic Emirates. Huang and Tseng (2010) investigate the relationship between oil price and nominal exchange rate by using different kind of oil types and find bidirectional causality for U.S.A.Yanagisawa (2010) examines the relationship for U.S.A. and implies that bidirectional casuality is valid previously, but casuality running from exchange rate to oil price dissappears in the last year of analysis. Mohammadi and Jahan-Parvar (2008) find bi-directional causality for Gabon, Indonesia, Nigeria and Saudi Arabia.

The fourth group of studies indicates that there is no causal relationship (the neutrality) between variables, implying that oil price and exchange rates do not provide a predictive power with respect to each other. The empirical evindence on the neutrality between oil prices and exchange rates is supported by Bjorvik et al. (1998), Habib and Kalamova (2007) and Bjornland and Hungnes (2008) for Norway, Habib and Kalamova (2007) for Saudi Arabia, Wu et al. (2011) for U.S.A; Mohammadi and Jahan Parvar (2010) for thirteen oil exporting countries; and Jahan-Parvar and Mohammadi (2008) for Algeria, Bahrain, Kuwait and Mexico.

\section{Econometric Methods}

\subsection{Hatemi-J (2006) Bootstrap Process-Based Toda-Yamamoto (1995) Linear Granger Causality Type}

In a standard Granger causality analysis, zero restrictions based on the Wald principle are imposed on the lagged coefficients obtained from the estimation of Vector Autoregressive (VAR) model. However, the Wald statistic may lead to nonstandard limiting distributions depending upon the co-integration properties of the VAR system that these nonstandard asymptotic properties stem from the singularity of the asymptotic distributions of the estimators (Lütkepohl, 2004). The Toda and Yamamoto (1995) (TY, hereafter) procedure overcomes this singularity problem by augmenting VAR model with the maximum integration degree of the variables. In addition to this advantage, the TY approach does not require testing for co-integration relationships and estimating the vector error correction model and is robust to the unit root and co-integration properties of the series.

The standard Granger (1969) causality analysis requires estimating a VAR $(p)$ model in which $p$ is the optimal lag length(s). In the TY procedure, the following VAR $(p+d)$ model is estimated that $d$ is the maximum integration degree of the variables.

$$
y_{t}=v+A_{1} y_{t-1}+\cdots+A_{p} y_{t-p}+\cdots+A_{p+d} y_{t-(p+d)}+\mu_{t} .
$$

where $y_{t}$ is vector of $k$ variables, $v$ is a vector of intercepts, $\mu_{t}$ is a vector of error terms and $A$ is the matrix of parameters. The null hypothesis of no-Granger causality against the alternative hypothesis of Granger causality is tested by imposing zero restriction on the first $p$ parameters. The so-called modified Wald (MWALD) statistic has asymptotic chi-square distribution with $p$ degrees of freedom irrespective of the number of unit roots and of the co-integration relations.

Hacker and Hatemi-J (2006) investigate the size properties of the MWALD test and find that the statistic with asymptotic distribution poorly performs in small samples. $\otimes$ the Kronecker product, $C=p \times n(1+n(p+d))$ a selector matrix, $S_{U}$ variance-covariance matrix of residuals, $\hat{\beta}=v e c(\hat{D})$ and vec is the column-stacking operator as the MWALD test statistics;

$$
M W A L D=(C \hat{\beta})^{\prime}\left[C\left(\left(Z^{\prime} Z\right)^{-1} \otimes S_{U}\right) C^{\prime}\right]^{-1}(C \hat{\beta}) \square \chi_{p}^{2}
$$

Monte Carlo simulation of Hacker and Hatemi-J (2006) shows that the MWALD test based on the bootstrap distribution has much smaller size distortions than those of the asymptotic distribution. Hacker and Hatemi-J (2006) extends the TY approach based on the bootstrapping method developed by Efron (1979). In this new approach that is so-called the leveraged bootstrap Granger causality test, the MWALD statistic is compared with the bootstrap critical value instead of the asymptotic critical value.

\subsection{Frequency domain causality test}

While conventional time domain causality tests produce a single test statistic for the interaction between variables in concern, frequency domain methodology generates tests statistics at different frequencies across spectra. This is contrary to the implicit assumption of the conventional causality analysis that a single test statistic summarizes the relation between variables, which is expected to be valid at all points in the frequency distribution. Frequency domain approach to causality thereby permits to investigate causality dynamics at different frequencies rather than relying on a single statistics as is the case with the conventional time domain analysis (Ciner, 2011). Hence, it seems to be very meaningful to carry out frequency domain causality to better understand temporary and permanent linkages between oil prices and exchange rates in the Romania. Details of frequency domain approach are given in the appendix A. 


\section{Data}

The exchange rate is defined as the foreign currency price of the U.S. dollar, concluding that the dollar appreciates as the nominal value of exchange rate rises. Real exchange rates (RER) are constructed using consumer price indices. The world price of oil, quoted in U.S. dollars, is chosen as representative of the general movement in oil prices over the period. To obtain the real oil price (ROP), the U.S. dollar price of oil was converted to domestic prices using the U.S. dollar exchange rate and then deflated by the domestic consumer price index. We employ monthly data belonging o period between November 2004 and December 2011. All the data is obtained from the International Financial Statistics published by IMF. The descriptive statistics are reported in table 1 . It seems that data characteristics are slightly different in each series. First of all, as expected, the mean of the real exchange rate is higher than real oil price. According to the standard deviation and coefficient of variation of the real oil price is higher than real exchange rate. However, kurtosis value of real exchange rate is smaller than real oil price.

\begin{tabular}{lllllll}
\hline Time Span & Variable & Mean & Std. Dev. & Coef. of var. & Skewness & Kurtosis \\
\hline November 2004- & RER & 4.665 & 0.057 & 0.012 & -0.062 & 3.675 \\
December 2011 & ROP & 0.538 & 0.202 & 0.375 & -0.28 & 2.737
\end{tabular}

Table 1. Descriptive Statistics Notes: Coefficient of variation is the ratio of standard deviation to mean. Descriptive statistics are for log series. ROP: real oil prices, RER: real exchange rates.

\section{Empirical Findings}

Prior to the identification of possible causality between the real exchange rates and the real oil prices, it is necessary to determine integration degree of variables. In that respect, we employ a battery of the unit root tests developed by Dickey and Fuller (1978 and 1981) (henceforth ADF), Phillips and Perron (1988) (henceforth PP), Elliot et al. (1996) (henceforth DF-GLS), and Kwaitkowski et al. (1992) (henceforth KPSS). The results from the unit root tests in table 2 show that ADF, PP and DF-GLS test do not reject the null of a unit root for the levels of real exchange rate and real oil price. When the ADF, PP and DF-GLS tests are applied to the first differences of the variables, the results indicate that all variables are stationary. Consistent with these results, the KPSS test for the null hypothesis also shows that the variables are stationary in their first differences. The unit root analyses thereby imply that the variables are integrated of order one. Accordingly, the maximum integration order (d) of the variables equal to one in the Toda Yamamoto linear Granger causality analysis.

\begin{tabular}{|l|l|l|l|l|l|}
\hline & & ADF & DF-GLS & PP & KPSS \\
\hline Levels & & & & & \\
\hline \multirow{3}{*}{ Intercept } & RER & $-2.800(1)^{*}$ & $-0.803(1)$ & $-3.205(3)^{* *}$ & $0.223^{*}$ \\
\cline { 2 - 6 } & ROP & $-3.039(2)^{* *}$ & $-2.236(2)^{* *}$ & $-2.247(4)$ & 0.416 \\
\hline \multirow{2}{*}{$\begin{array}{c}\text { Intercept and } \\
\text { Trend }\end{array}$} & RER & $-2.690(1)$ & $-1.340(1)$ & $-2.961(1)$ & 0.222 \\
\cline { 2 - 6 } & ROP & $-3.508(2)^{* *}$ & $-3.489(2)^{* *}$ & $-2.661(4)$ & $0.078^{* *}$ \\
\hline First-differences & & & & & \\
\hline \multirow{3}{*}{$\begin{array}{l}\text { Intercept } \\
\text { Intercept and } \\
\text { Trend }\end{array}$} & RERR & $-6.701(0)^{* * *}$ & $-3.873(0)^{* * *}$ & $-6.618(4)^{* * * *}$ & $0.373^{* * *}$ \\
\cline { 2 - 6 } & ROPR & $-7.557(0)^{* * *}$ & $-2.351(1)^{* * *}$ & $-7.710(3)^{* * *}$ & $0.043^{* * *}$ \\
\cline { 2 - 6 } & RERR & $-6.832(0)^{* * *}$ & $-5.886(0)^{* * *}$ & $-6.741(4)^{* * *}$ & $0.115^{* * *}$ \\
\hline
\end{tabular}

Table 2. Results of the Unit Root Test Notes: For the KPSS test: * The asymptotic critical values of LM statistic for intercept 0.739, 0.463 at the \%1 and \%5 levels, ** the asymptotic critical values of LM statistic for trend and intercept 0.216, 0.146 at the $\% 1$ and $\% 5$ levels.

For the DF-GLS test: *The asymtotic critical values for without trend $-2.591,-1.944$ at the $\% 1$ and $\% 5$ levels. ** The asymtotic critical values for with trend $-3.602,-3.177$ at the $\% 1$ and $\% 5$ levels. The figures in parenthesis denote the number of lags in the tests that ensure white noise residuals. They were estimated through the Schwarz criterion.

For the ADF test: * shows the results of Dickey Fuller test in the case of zero lag length and lag length choosen due to SIC criteria.** For the ADF test, the Mac Kinnon(1996) critical values for with constant -.3.485, -2.885, 2.579 at the $1 \%, 5 \%$ and $10 \%$ levels. The critical values for with constant and trend $-4.035,-3.447$ ve -3.148 at the $1 \%, 5 \%$ and $10 \%$ levels, respectively.

For the PP test: *Values in the paranthesis show bandwiths obtained according to Newey-West using Bartlett Kernel criteria. ** For the PP test Mac Kinnon(1996) critical values for with constant $-3.483,-2.884,-2.579$ at the $1 \%, 5 \%$ and $10 \%$ levels.the critical values for with constant and trend $-4.033,-3.446$ and -3.148 at the $1 \%$ $5 \%$ and $10 \%$ levels, respectively. 
In the first step we employ bootstrap process based Toda Yamamoto (1995) linear causality (TY hereafter) test. Table 2 shows the results of bootstrap process based linear TY Granger type causality test results. As indicated in the table 2 statistics for both tests are higher than critical values obtained by replication for 10.000 times. According to test results, there is a uni-directional causality running from real oil price to real exchange rate.

Real oil prices to real exchange rates

\begin{tabular}{|c|c|c|c|c|}
\hline \multirow{2}{*}{ MWALD } & \multirow[b]{2}{*}{ p-value } & \multicolumn{3}{|c|}{ Bootstrap critical values } \\
\hline & & $1 \%$ & $5 \%$ & $10 \%$ \\
\hline 11.369 & 0.000 & 12.499 & 8.240 & 6.444 \\
\hline \multicolumn{5}{|c|}{ Real exchange rates to real oil prices } \\
\hline \multicolumn{5}{|c|}{ Bootstrap critical values } \\
\hline MWALD & p-value & $1 \%$ & $5 \%$ & $10 \%$ \\
\hline 0.743 & 0.862 & 12.265 & 8.335 & 6.674 \\
\hline
\end{tabular}

Table 3. Results of Linear Granger Causality Test Note: p-value denotes asmptotic chi-sqaure distribution. The AIC was used to determine the optimal lag lengths for $\operatorname{VAR}(p+d)$ models. Numbers in brackets are p-values. The number of replication is 10000.

In the second step, we employ Breitung and Candelon's (2006) analysis which permits to decompose the causality test statistic into different frequencies. We calculate the test statistics at a high frequency of $\omega_{i}=2.5$ and $\omega_{i}=2.0$ to examine short term causality, $\omega_{i}=1.00$ and $\omega_{i}=1.50$ to examine medium term causality and finally $\omega_{i}=$ .01 and $\omega_{i}=.05$ to investigate long term causality. By doing so, we are able to learn both temporary and permanent relations between variables. According to results of frequency domain causality test, we imply that there is no effect of real oil prices on real exchange rate in any time period. Results show that the causal relationship running from real exchange rate to real oil price is valid for long and medium term.

\begin{tabular}{|c|c|c|c|c|c|c|}
\hline \multicolumn{7}{|c|}{ Real exchange rate to real oil price } \\
\hline \multirow[b]{2}{*}{$\omega_{i}$} & \multicolumn{2}{|c|}{ Long Term } & \multicolumn{2}{|c|}{ Medium Term } & \multicolumn{2}{|c|}{ Short Term } \\
\hline & 0.01 & 0.05 & 1.00 & 1.50 & 2.0 & 2.50 \\
\hline \multicolumn{6}{|c|}{ Real oil price to real oil price } & $4.503 *$ \\
\hline & Long T & & Mediu & & Short T & \\
\hline \multirow[t]{2}{*}{$\omega_{i}$} & 0.01 & 0.05 & 1.00 & 1.50 & 2.00 & 2.50 \\
\hline & 1.563 & 3.089 & 0.391 & 0.380 & 1.273 & 0.157 \\
\hline
\end{tabular}

Table 4. Results for frequency domain causality test Notes: The lag lengths for the VAR models are determined by SIC. F-distribution with $(2, T-2 p)$ degrees of freedom equals 5.99.

While linear causality analysis results imply existence of causality running from real oil price to real exchange rate in Romania, frequency domain causality results find evidence the causality running from real exchange rate to real oil price on the longer periods. As can been, both the time domain and frequency domain causality tests imply different results.

\section{Conclusions}

In this study, we examine monthly data belonging November 2004- December 2011 period in order to find whether there is an interaction between oil price fluctuations and exchange rate volatilities in the Romanian economy. In this regard, we employ linear causality test developed by Hatemi-J (2006) and frequency domain causality test developed by Candelon and Breitung (2006).

The results imply that time domain and frequency domain causality approaches imply different results. While time domain causality analysis indicates causality running from real oil price to real exchange rate, frequency domain causality analysis implies reverse causality in all time frequencies.

According to frequency domain causality analysis results, it is clear that oil price shocks do not affect exchange rate in the Romanian economy. This result is consistent with Romanian's energy dependency level. Low energy dependency prevents the effects of oil price shocks. Also relatively low share of oil in total energy consumption helps to explain the absence of the relationship running from oil price to exchange rate. On the other hand, existence of causality running from exchange rate to oil price on the medium and long run supports the Coudert et al.'s (2008) implications about the price elasticity of oil demand and oil supply. The effect of exchange rate fluctuations appears on the longer periods due to inelasticity of oil demand and supply on the short run. 


\section{References}

- $\quad$ Akram, Q. F., 2004. Oil prices and exchange rates: Norwegian evidence. Econometrics Journal 7, 476-504.

- Aleisa, E. A., Dibooglu, S., 2002. Sources of real exchange rate movements in Saudi Arabia. Journal of Economics and Finance 26 (1), 101-110.

- Amano, R. A., van Norden, S., 1998. Oil prices and the rise and fall of the U.S. real exchange rate. Journal of International Money and Finance 17, 299-316.

- $\quad$ Bergstrand, J. H., 1991. Structural determinants of real exchange rates and national price levels: Some empirical evidence. American Economic Review 81 (1), 325-334.

- $\quad$ Bjornland, H. C., Hungnes, H., 2008. The commodity currency puzzle. The IUP Journal of Monetary Economics 0(2), 7-30.

- Branson, W. H., 1981. Macroeconomic determinants of real exchange rates. NBER Working Paper no. 801.

- Breitung, J., Candelon, B., 2006. Testing for short and long-run causality: A frequency domain approach. Journal of Econometrics 12, 363-378.

- Bjørvik, L. M., Mork, K. A., Uppstad, B. H., 1998. Påvirkes kursen på norske kroner av verdensprisen på olje? (Is the exchange rate for the norwegian Krone affectted by the real oil price?), Norsk Økonomisk Tidsskrift 1, 1-33.

- Chaudhuri, K., Daniel, B. C., 1998. Long-run equilibrium real exchange rates and oil prices. Economic Letters 58, 231-238.

- Chen, S. S., Chen, H. C., 2007. Oil prices and real exchange rates. Energy Economics 29, 390-404.

- Ciner, C., 2011. Eurocurrency interest rate linkages: A frequency domain analysis. International Review of Economics and Finance 20, 498-505.

- Clarida, R., Gali, J., 1994. Sources of real exchange rate fluctuations: How important are nominal shocks. Carnegie-Rochester Conference Series on Public Policy 41 (1), 1-56.

- $\quad$ Coudert, V., Mignon, V., Penot, A., 2008. Oil price and the dollar. Energy Studies Review 15 (2).

- Dawson, J. C., 2003. The effect of oil prices on exchange rates: A case study of the Dominician Republic. The Park Place Economist 14, 23-30.

- Dickey, D. A., Fuller, W. A., 1979. Distribution of the estimators for autoregressive time series with a unit root. Journal of the American Statistical Society 75, 427-431.

- Dickey, D. A., Fuller, W. A., 1981. Distribution of the estimators for autoregressive time series with a unit root. Econometrica 49, 1057-1072.

- Dobrota, G., 2007. The foreign currency regime and policy in Romania. MPRA paper no. 11433.

- Dornbusch, R., 1980. Exchange rate economics: Where do we stand?. Brookings Papers on Economic Activity 1, 143-186.

- Elliot, G., Rothenberg, T. J., Stock, J. H., 1996. Efficient tests for an autoregressive unit root. Econometrica 64 (4), 813-836.

- European Commission, 2008. FDI in Romania: from low-wage competition to higher value-added sectors. ECFIN Country Focus 5 (3), 1-6.

- European Commission, 2007. Energy fact sheet Romania.

- Faruqee, H., 1995. Long-run determinants of the real exchange rate: A stock-flow perspective. International Money Fund Staff Papers 42 (1), 80-107.

- Geweke, J., 1982. Measurement of linear dependence and feedback between multiple time series. Journal of the American Statistical Association 77, 304-313.

- Golub, S. S., 1983. Oil price and exchange rates. The Economic Journal 93 (371), 576-593.

- Groen, J. J. J., Pesenti, P. A., 2010. Commodity prices, commodity currencies and global economic developments. NBER Working Papers no. 15743.

- Habib, M. M., Kalamova, M. M., 2007. Are there oil currencies? The real exchange rate of oil exporting countries. European Central Bank Working Paper Series no. 839.

- Hasanov, F., 2010. The impact of real oil price on real effecive exchange rate: The case of Azerbaijan. German Institute for Economic Research Discussion Paper no. 1041.

- Hosoya, Y., 1991. The decomposition and deasurement of the interdependence between second-order stationary process. Probability Theory and Related Fields 88, 429-444. 
- Huang, A.Y., Tseng, Y. H., 2010. Is crude oil price affected by the U.S. dollar exchange rate?. International Research Journal of Finance and Economics 58, 109-120.

- IMF, 2000. World Economic Outlook.

- Indjehagopian, J. P., Lantz, F., Simon, V., 2000. Dynamics of heating oil market prices in Europea. Energy Economics 22, 225-252.

- Issa, R., Lafrance, R., Murray, J., 2006. The turning back tide: Energy prices and the Canadian Dollar. Bank of Canada Working Paper no. 2006-29.

- Jahan-Parvar, M. R., Mohammadi, H., 2008. Oil prices and real exchange rates in oil-exporting countries: A bounds testing approach. University Library of Munich no. 13435.

- Korhonen, I., Juurikkala, T., 2009. Equilibrium exchange rates in oil exporting countries. Journal of Economisc and Finance 33, 71-79.

- Krugman, P., 1983a. Oil and the dollar. NBER Working Paper Series no. 554.

- Krugman, P., 1983b. Oil shocks and exchange rate Dynamics, in Frenkel, J.A. (Eds.) Exchange Rates and International Macroeconomics, University of Chicago Press.

- $\quad$ Kutan, A.M. and Wyzan, M.L., 2005. Explaining the real exchange rate in Kazakhstan, 1996-2003: Is Kazakhstan vulnerable to the Dutch Disease?. Economic Systems 29, 242-255.

- $\quad$ Kwiatkowski, D., Phillips, P.C.B., Schmidt, P., Shin, Y., 1992. Testing the null hypothesis of stationary against the alternative of a unit root. Journal of Econometrics 54, 159-178.

- Linn, J. F., 2003. Transition in Central and South East Europe and the CIS: The energy dimension. The World Bank at Conference on Restructuring the Energy Sector in Transition Countries Lessons Learned and Challenges Ahead, Leipzig, Germany.

- $\quad$ Lizardo, R.A., Mollick, A.V., 2010. Oil price fluctuations and the U.S. dollar exchange rates. Energy Economics 32, 399-408.

- Marcu, N., 2008. Romania's exchange rate policy towards its European Monetary Union membershipprospects and challenges. Romanian Journal of Economic Forecasting 9(1), 175-181.

- Mark, N. C., Choi, D.Y., 1997. Real exchange rate prediction over long horizons. Journal of International Economics 43(1-2), 29-60.

- Mendez-Carbajo, D., 2011. Energy dependence, oil prices and exchange rates: The Dominican economy since 1990. Empirical Economics 40(2), 509-520.

- Mohammadi, H., Jahan-Parvar, M. R., 2010. Oil prices and exchange rates in oil-exporting countries: Evidence from TAR and M-TAR models. Journal of Economics and Finance 23.

- Narayan, P. K., Narayan, S., Prasad, A., 2008. Understanding the oil price-exchange rate nexus for The Fiji Islands. Energy Economics 30, 2686-2696.

- Nikbakht, L., 2010. Oil prices and exchange rates: The case of OPEC. Business Intelligence Journal 3 (1), 83-92.

- $\quad$ Olomola, P. A., Adejumo, A. V., 2006. Oil price shocks and macroeconomic activities in Nigeria. International Research Journal of Finance and Economics 3, 28-34.

- $\quad$ Phillips, P. C. B., Perron, P., 1988. Testing for a unit root in time series regressions. Biometrica 75, 335-346.

- Popa, L. P., 2009. Trends of the Romanian foreign trade in transition period. Ştiinte Economice, 442-457.

- Sadorsky, P., 2000. The empirical relationship between energy futures prices and exchange rates. Energy Economics 22, 253-266.

- $\quad$ Rickne, J., 2009. Oil prices and real exchange rate movements in oil-exporting countries: The role of institutions. Research Institute of Industrial Economics Working Paper Series no. 810.

- Schmidbauer, H., Rösch, A., 2008. Volatility spillovers between crude oil prices and U.S. dollar to Euro exchange rates. Unpublished paper.

- Usama, A. M., Normee, C. S., 2009. The impact of oil prices on the real exchange rate of the dirham: A case study of the United Arab Emirates. MPRA Paper no.23493.

- Wu, C. C., Chung, H., Chang, Y. H., 2012. The economic value of co-movement between oil price and exchange rate using copula-based GARCH models. Energy Economics 34(1), 270-282.

- Yanagisawa, A., 2010. Relationship among crude oil prices, share prices and exchange rate. IEEJ, November.

- Yousefi, A., Wirjanto, T. S., 2004. The empirical role of the exchange rate on the crude oil price formation. Energy Economics 26, 783-799. 
- Yousefi, A., Wirjanto, T. S., 2005. A stylized exchange rate pass-through model of crude oil price formation. OPEC Review September 2005, 177-197.

- Zalduendo, J., 2006. Determinants of Venezuela's equilibrium real exchange rate. IMF Working Paper no. WP/06/74.

- Zhang, Y. J., Fan, Y., Tsai, H. T., 2008. Spill over effect of U.S. dollar exchange rate on oil prices. Journal of Policy Modelling 30, 973-991.

\section{Appendix}

To test for causality based on frequency domain, Geweke (1982) and Hosoya (1991) defined causality;

$$
M_{y \rightarrow x}(\omega)=\log \left[\frac{2 \pi f_{x}(\omega)}{\left|\psi_{11}\left(e^{-i \omega}\right)\right|^{2}}\right]=\log \left[1+\frac{\left|\psi_{12}\left(e^{-i \omega}\right)\right|^{2}}{\left|\psi_{11}\left(e^{-i \omega}\right)\right|^{2}}\right]
$$

if $\left|\psi_{12}\left(e^{-i \omega}\right)\right|^{2}=0$ that $\mathrm{y}$ does not cause $\mathrm{x}$ at frequency $\omega$. If components of $z_{t}$ are $\mathrm{I}(1)$

and cointegrated, $\Theta(L)$ has a unit root. Breitung and Candelon (2006) investigate the causal effect of $M_{y \rightarrow x}(\omega)=0$ if $\left|\psi_{12}\left(e^{-i \omega}\right)\right|^{2}=0$. The null hypothesis is equivalent to a linear restriction on the VAR coefficients. $\psi(L)=\Theta(L)^{-1} G^{-1}$ and $\psi_{12}(L)=-\frac{g^{22} \Theta_{12}(L)}{|\Theta(L)|}$, with $g^{22}$ as the lower diagonal element of $G^{-1}$ and $|\Theta(L)|$ as the determinant of $\Theta(L)$, it follows $y$ does not cause at frequency $\omega$ if

$$
\left|\Theta_{12}\left(e^{-i \omega}\right)\right|=\left|\sum_{k=1}^{p} \theta_{12, k} \cos (k \omega)-\sum_{k=1}^{p} \theta_{12, k} \sin (k \omega) i\right|=0
$$

with $\theta_{12, k}$ denoting the (1,2)-element of $\Theta_{k}$. Thus for $\left|\Theta_{12}\left(e^{-i \omega}\right)\right|=0$,

$$
\begin{aligned}
& \sum_{k=1}^{p} \theta_{12, k} \cos (k \omega)=0 \\
& \sum_{k=1}^{p} \theta_{12, k} \sin (k \omega)=0
\end{aligned}
$$

Breitung and Condelon's (2006) applied to linear restrictions (14) and (15) for $\alpha_{j}=\theta_{11, j}$ and $\beta_{j}=\theta_{12, j}$. Then the VAR equation for $x_{t}$ can be implied as

$x_{t}=\alpha_{1} x_{t-1}+\ldots+\alpha_{p} x_{t-p}+\beta_{1} y_{t-1}+\ldots+\beta_{p} y_{t-p}+\varepsilon_{1 t}$

and the null hypothesis $M_{y \rightarrow x}(\omega)=0$ is equivalent to the linear restriction with $\beta=\left[\beta_{1}, \ldots, \beta_{p}\right]^{\prime}$

$H_{0}: \quad R(\omega) \beta=0$

and

$$
R(\omega)=\left[\begin{array}{cccc}
\cos (\omega) & \cos (2 \omega) & \ldots & \cos (\mathrm{p} \omega) \\
\sin (\omega) & \sin (2 \omega) & \ldots & \sin (\mathrm{p} \omega)
\end{array}\right]
$$

The causality measure for $\omega \in(0, \pi)$ can be tested a Standard F-test for the linear restrictions imposed by Eq.(14) and Eq. (15). The test procedure follows an F- distribution with (2, T-2p) degrees of freedom. 